\title{
A TIPOGRAFIA NO CONTEXTO DO LIVRO DIGITAL INFORMATIVO: ANÁLISE DE UM EXEMPLO
}

\author{
Maíra Woloszyn \\ Universidade Federal de Santa Catarina \\ maira.projetar@gmail.com \\ Marcele Cassol Licht \\ Universidade Federal de Santa Catarina \\ marcele.licht@gmail.com \\ Berenice Santos Gonçalves \\ Universidade Federal de Santa Catarina \\ bereni.gon@gmail.com
}

Resumo: Devido ao potencial oferecido pelos dispositivos eletrônicos as publicações estão sendo desenvolvidas para o acesso digital, além do formato impresso. Nesse contexto, os livros digitais oferecem aos leitores novas opções para a leitura. A tipografia é considerada como componente essencial para as publicações e pode assumir diferentes propósitos. Em vista disso, este estudo tem como objetivo verificar o uso e as formas de aplicações da tipografia em livros digitais informativos, com base em um exemplo. Por meio do referencial teórico foi possível sustentar uma análise qualitativa e descritiva sobre um exemplar escolhido, a partir das seguintes propriedades: legibilidade e leiturabilidade, o espaçamento, tamanho e cor, movimento e a hierarquia da tipografia. Como resultado, destacam-se formas de uso da tipografia que podem beneficiar a construção das informações nos livros digitais informativos, tais como links, elementos interativos e botões. Identificou-se, ainda, que a tipografia em movimento foi utilizada, porém de forma insipiente de acordo com os potenciais que ainda podem ser explorados nesse contexto.

Palavras-chave: Livro digital, Livro informativo, Design, Tipografia.

Abstract: Because of the potential offered by electronic devices, publications are being developed for digital access, in addition to the printed format. Thereby, digital books offer to readers new options for reading. Typography is considered as an essential component for publications and can take different purposes. From this, this paper aims to check how typography is use on informative digital books, based on example. Through the theoretical framework was possible develop a qualitative and descriptive analysis of a selected copy. The analyzed properties are: legibility and readability, spacing, size and color, movement and the hierarchy of typography. As a result, there are the forms of use of 
typography that can advantage the information in the informative digital books, such as links, interactive elements and buttons. It was found also that the typography in motion was used, but little significance according to the potential that can be explored in this context.

Key-words: Digital book, Informative book, Design, Typography.

\section{INTRODUÇÃO}

Em virtude do desenvolvimento tecnológico dos meios digitas, abriram-se novas possibilidades de atuação para o Design. A apresentação interativa de informação oferece novas oportunidades, pois as publicações impressas não competem com formas de publicações audiovisuais (BONSIEPE, 2011).

Após o desenvolvimento dos computadores e das mídias digitais um novo habitat para a escrita surgiu, assim ocorreu uma ampliação quanto às possibilidades para as publicações. O livro, no meio digital, adquire propriedades híbridas passando a assumir diferentes formas de expressão incluindo formatos que disponibilizam recursos multimídia e interativos (SANTAELLA, 2013), pois são apresentadas por meio de uma interface. Compreendida como o espaço onde acontece a interação entre corpo, ferramenta e objetivo da ação, a interface revela o conteúdo comunicativo das informações e permite ao usuário navegar no espaço informacional sem perder a orientação e de acordo com seus interesse (BONSIEPE, 1997).

O livro impresso e o livro digital são publicações distintas que oferecem ao leitor diferentes opções para a leitura. Entre as tipologias do livro, Haslam (2010) diferencia os livros de ficção dos livros informativos. O autor ressalta que a elaboração de um livro informativo torna-se mais flexível que o livro ficcional, pois as páginas são construídas por diferentes recursos, como imagens, mapas, gráficos, diagramas e tabelas que permitem ao leitor a oportunidade de comparar e analisar as informações.

Os Livros informativos são publicações de conteúdo não ficcional. São obras que descrevem fatos, expõem, estabelecem analogias, utilizam linguagem técnica e promovem a divulgação científica (GARRALÓN, 2015).

Carreras (2011) define três atributos para qualificar os livros informativos. Para o autor, os livros informativos precisam ser Científicos, Atuais e Compreensíveis. 0 atributo Científico caracteriza a veracidade das informações quanto às fontes utilizadas. Além disso, para que as informações sejam confiáveis elas precisam ser Atuais, pois os conhecimentos estão sujeitos a novas pesquisas e descobertas. A forma de abordagem das informações precisa ser Compreensível, ou seja, utilizar discurso apropriado ao público, assim como, apresentar os recursos necessários.

O livro digital informativo, como um tipo específico de publicação digital, pode absorver as características dos meios digitais para potencializar a expressão de seus conteúdos. Nesse contexto, a tipografia, responsável por compor palavras e textos, está enfrentando desafios com as mídias digitais, uma vez que estão se tornando cada vez mais visuais. Essa tecnologia permitiu um novo entendimento à tipografia, pois esse recurso gráfico está se tornando mais expressivo nas publicações digitais (LEEUWEN, 2006). Assim, o presente artigo tem como pergunta norteadora: como a tipografia pode ser utilizada em livros digitais informativos? 
Para tanto, o estudo apresenta uma análise realizada sobre um livro digital informativo, usando como base os autores que compõem o referencial teórico, como Priscila Farias (2002), Robert Bringhurst (2005), Timothy Samara (2011), Ellen Lupton (2006, 2015), João Aranda Brandão (2015), entre outros. Como resultado, o artigo relaciona as características da tipografia com os tipos de leitura, diferenciando a leitura estética e leitura eferente, que podem ser contempladas pelos livros digitais informativos. Além disso, foi possível identificar formas de uso da tipografia, como também, ressaltar os potenciais que ainda podem ser explorados nos livros digitais informativos.

\section{TIPOGRAFIA}

Em publicações impressas ou digitais, os aspectos visuais são baseados nas necessidades de leitura e compreensão da informação apresentada. Mesmo nas publicações onde as imagens prevalecem, é necessário que haja refinamento nos textos para garantir sintonia entre todos os componentes do produto. (SAMARA, 2011a). Parte intrínseca do ato de compreender textos, é a tipografia (BONSIEPE, 1997), compreendida como a área que estuda a história, anatomia, desenvolvimento e uso dos tipos.

Estamos envolvidos com a tipografia em todos os momentos do dia, seja nas embalagens de alimentos, cartazes espalhados nas ruas ou em dispositivos móveis digitais (SAMARA, 2011b), "a tipografia precisa frequentemente chamar a atenção para si própria antes de ser lida. Para que seja lida, precisa, contudo, abdicar da mesma atenção que despertou" (BRINGHURST, 2005, p. 23). Quando tratamos da leitura em ambientes digitais, a tipografia merece ainda mais atenção, pois as publicações digitais transformaram leitores em usuários, que interagem com o conteúdo e respondem a ele de maneiras não lineares e muitas vezes imprevisíveis (LUPTON, 2015, p. 79).

Sendo formas de leitura encontradas em livros digitais, Carter (1990), citada por Garraón (2015), diferencia a leitura estética e a leitura eferente. A autora argumenta que as obras de fiç̧ão contribuem para uma leitura estética, enquanto que, no livro informativo a leitura é eferente.

A Leitura Estética tem como propósito comover o leitor e provocar emoções. Nesse sentido, o leitor demonstra maior envolvimento pelos aspectos afetivos. A leitura estética ocorre, com frequência, durante a leitura de obras ficcionais, pois corresponde às diferentes sensações proporcionadas no decorrer da história.

A Leitura Eferente diferencia-se da leitura estética, pois a atenção do leitor está focada em selecionar informações que serão úteis para a apropriação e uso posterior à leitura. Em vista disso, a Leitura Eferente é própria do livro informativo, pois deve conduzir o leitor pelo conteúdo apresentado.

As delimitações não são rígidas, uma vez que os dois tipos de leitura podem coexistir em uma mesma publicação. Livros informativos podem incluir o apelo emocional como estratégia de incentivo à leitura (VILLAREJO, 2009; GARRAÓN, 2011).

A tipografia auxilia os leitores a navegarem pelo conteúdo, seja por meio de um simples recuo no início de um parágrafo que sinaliza a entrada de uma nova ideia ou de um link que pode direcionar o usuário para outro local (LUPTON, 2006).

Embora muito associada à composição de textos, a tipografia também pode assumir outras formas de expressão, como a de imagem. Enquanto, em um bloco de texto, as palavras fazem parte de uma sequência e podem "fluir de uma página, coluna 
ou caixa para outra" (LUPTON, 2006, p.63), "quando uma letra ou palavra assume qualidades pictóricas além daquelas que definem sua forma, torna-se uma imagem autossuficiente, e seu potencial de impacto é imenso" (SAMARA, 2011a, p.32).

Em publicações digitais, a tipografia além de configurar textos e compor imagens, ainda pode aparecer combinada com movimento, onde tipos podem apresentar modificações na sua estrutura e forma ou se deslocar pela tela.

\subsection{Tipografia estática}

Conforme argumenta Lupton (2015, p. 165) "a maioria das letras é criada para ser estática, frontal e vertical". Por isso, em meios digitais, adota-se o termo "tipografia estática" para se referir ao estudo dos tipos que não apresentam movimentos de deslocamento ou metamorfose. Essa terminologia é usada, também, por que "a atual compreensão da natureza da tipografia assume que ela seja estática com propriedades de forma e cor" (BROWNIE, 2007, p. 1, tradução nossa). Para compreender a tipografia em publicações digitais, é necessário resgatar alguns princípios da tipografia clássica, muito abordados para os meios impressos.

Os principais fatores a se considerar, dizem respeito à legibilidade e leiturabilidade da tipografia. Inicialmente, deve-se compreender a distinção dos dois termos. A leiturabilidade refere-se à compreensão do leitor de uma palavra ou frase, como um todo, e ao conforto visual desta leitura. Ela busca avaliar quanto tempo o leitor pode se dedicar a um trecho de texto sem se cansar visualmente. Já a legibilidade discute a clareza dos caracteres de forma isolada e avalia a velocidade com que um caractere pode ser reconhecido (FARIAS, 2002). Porém, "a legibilidade das letras tipográficas não dependem apenas de sua forma (...), mas também do vazio esculpido entre elas e à sua volta" (BRINGHURST, 2005, p. 43). Essa relação entre forma e contraforma é o que define o espacejamento ideal para uma fonte, tanto dos espaços entre letras, quanto entre palavras, linhas de texto e parágrafos. Esses espaços são essenciais para criar uma uniformidade no texto e minimizar as distrações para o leitor (SAMARA, 2011a).

Embora os princípios da tipografia tradicional ajudem na compreensão do assunto mesmo com foco em publicações digitais, alguns fatores devem ser ajustados para garantir o conforto de leitura na tela, como a escolha do tamanho da fonte que será utilizado. Esse parâmetro para meios digitais tem orientações diferentes dos para meio impresso por que, devido à luminosidade do visor digital, a distância do olhar com que um usuário se posiciona de um computador, ou de um dispositivo de leitura digital, é maior do que a distância que se posiciona de um livro impresso. Isto, aliado ao fato de que a luz do visor pode tornar as letras imprecisas, faz com que as recomendações para o uso fontes em publicações digitais seja com tamanhos maiores do que os indicados para publicações impressas (LUPTON, 2015).

Outro fator que deve ser observado, principalmente em função da luz do visor digital, é a cor aplicada à tipografia. A escolha da cor deve ser feita com cuidado, pois em algumas situações o matiz escolhido juntamente com a luminosidade da tela, pode diminuir a legibilidade dos caracteres. Também, o uso das cores pode conferir a percepção de profundidade à tipografia, com isso, aplicados a fundos claros, um elemento mais escuro parece estar mais perto, enquanto um elemento mais claro parece recuar (SAMARA, 2011a). "O segredo para bons arranjos tipográficos é o contraste" (SAMARA, 2011b), sendo assim, para garantir a legibilidade e leiturabilidade 
dos textos, é necessário que as cores aplicadas à tipografia e ao fundo do produto apresentem contraste quando adicionadas à luminosidade da tela.

Além de se grande responsável por compor os textos que apresentam as informações em uma publicação, a tipografia "também acrescenta mensagem aos layouts, para além do que está literalmente expresso pela escrita em si" (SAMARA, 2011a, p. 22). Desta forma, os tipos também podem assumir outras funções nos livros digitais como a de botões, elementos de interação e imagens. Por isso, a verificação dos princípios citados pode colaborar no desenvolvimento de livros informativos digitais em relação ao uso da tipografia.

\subsection{Tipografia em movimento}

A partir do advento das novas tecnologias de informação e comunicação, a tipografia vem sendo removida dos limites da publicação impressa e inserida em projetos de diferentes meios como televisão, vídeo, cinema, web, entre outros. Essas tecnologias permitem o uso da tipografia de forma mais expressiva, com a inserção de textos e tipos combinados com movimento (TURGUT, 2012).

A tipografia em movimento trata da combinação desses dois recursos distintos - tipografia e movimento - e pode integrar diferentes conceitos como o de tecnologia, música, narrativa literária, entre outros (HOESTETLER, 2006). Ela pode se configurar como uma simples rolagem de texto, como os presentes nos créditos de filmes, ou como tipos que mudam sua localização na tela e textos que percorrem diversos caminhos (BROWNIE, 2007). Ainda, os caracteres e as palavras "não precisam moverse literalmente: elas podem aparecem e desaparecer, piscar letra por letra, ou mudar de escala, cor, camada e assim por diante" (LUPTON; PHILLIPS, 2008, p. 226).

Além de considerar todos os parâmetros já citados anteriormente para a tipografia estática - legibilidade e leiturabilidade, forma e contraforma da letra, espaçamento, tamanho da fonte e cor -, a tipografia em movimento necessita de atenção especial à questão do movimento. Ele é responsável por dar "vida a tipografia ao adicionar complexidade e dimensão a letras bidimensionais" (LUPTON, 2015, p. 165). Ainda, o movimento pode moldar o texto e imprimir a ele características importantes, e novos significados à mensagem que está sendo transmitida. Também permite uma maior eficiência na comunicação, uma vez que o movimento é um forte apelo à atenção do leitor, e pode direcioná-lo de acordo com a hierarquia projetada para a publicação (BRANDÃO, 2015).

Este recurso tem sido muito explorado principalmente no cinema, em créditos de filmes, e vídeos de clipes musicais. Ainda, é recorrente o uso da tipografia em movimento em livros digitais, telões urbanos e até mesmo com tipos que se movem de forma sutil ao abrir aplicativos de smartphones e tablets (LUPTON, 2015). Dificilmente a tipografia se apresenta de forma isolada, como único componente de um produto, especialmente em livros digitais. Ela se apresenta interligada com outros meios de informação, como cores, imagens e sons, que não devem ser tratados como algo externo à tipografia, uma vez que ao interagirem de maneiras distintas, podem adicionar significados diferentes à informação apresentada (LEEUWEN, 2006). 


\subsection{Propriedades da tipografia em tela}

A partir dos apontamentos abordados pelos autores nos subcapítulos anteriores, foi possível identificas propriedades tipográficas que foram agrupadas conforme mostra o quadro a seguir.

\begin{tabular}{|c|c|c|c|}
\hline PROPRIEDADES & AUTOR & ANO & CONTRIBUIÇÃO \\
\hline $\begin{array}{l}\text { Legibilidade e } \\
\text { leiturabilidade }\end{array}$ & Farias & 2002 & $\begin{array}{l}\text { A leiturabilidade diz respeito à compreensão } \\
\text { de uma palavra ou frase por parte de leitor e é } \\
\text { fundamental para o conforto da leitura, assim } \\
\text { como a legibilidade, que trata da clareza com } \\
\text { que os caracteres se apresentam. }\end{array}$ \\
\hline \multirow{2}{*}{ Espaçamento } & Samara & $2011 a$ & $\begin{array}{l}\text { Os espaços entre letras, palavras e linhas de } \\
\text { um texto são essenciais para criar } \\
\text { uniformidade e minimizar as distrações do } \\
\text { leitor. }\end{array}$ \\
\hline & Bringhurst & 2005 & $\begin{array}{l}\text { A legibilidade tipográfica não se diz respeito } \\
\text { apenas à forma das letras, mas também dos } \\
\text { espaços vazios em torno delas. }\end{array}$ \\
\hline \multirow[b]{2}{*}{ Cor e tamanho } & Samara & $2011 a$ & $\begin{array}{l}\text { As cores podem conferir percepção de } \\
\text { profundidade à tipografia. Os contrates são } \\
\text { essenciais para bons arranjos tipográficos. }\end{array}$ \\
\hline & Lupton & 2015 & $\begin{array}{l}\text { O tamanho da fonte utilizada deve ser } \\
\text { observada uma vez que, por causa da } \\
\text { luminosidade, a distância que o leitor se } \\
\text { posiciona do dispositivo móvel é maior da que } \\
\text { se posiciona de um livro impresso. }\end{array}$ \\
\hline \multirow{2}{*}{ Movimento } & Lupton & 2015 & $\begin{array}{l}\text { A tipografia, quando combinada com } \\
\text { movimento, ganha complexidade e dimensão. }\end{array}$ \\
\hline & Brandão & 2015 & $\begin{array}{l}\text { O movimento é um forte apelo à atenção do } \\
\text { leitor. }\end{array}$ \\
\hline \multirow[b]{2}{*}{ Hierarquia } & Brandão & 2015 & $\begin{array}{l}\text { A tipografia combinada com o movimento } \\
\text { pode conduzir o usuário de acordo com a } \\
\text { hierarquia do produto. }\end{array}$ \\
\hline & Lupton & 2006 & $\begin{array}{l}\text { A tipografia pode auxiliar o leitor a navegar } \\
\text { pelo conteúdo da publicação, seja com recuos } \\
\text { de parágrafo, links para conteúdo adicional ou, } \\
\text { até mesmo, com as diferenças de tamanho, } \\
\text { estilo de fonte e cor em títulos e palavras } \\
\text { destacadas. }\end{array}$ \\
\hline
\end{tabular}

Quadro 1 - Síntese das principais contribuições dos autores sobre a tipografia em tela.

Fonte: Elaborado pelas autoras com base nas pesquisas realizadas. 
Muitos pontos devem ser considerados ao desenvolver um livro digital, principalmente em relação à tipografia, uma vez que ela é a principal responsável por apresentar os textos de forma legível ao leitor. A partir da síntese de propriedades elaborada, foi possível desenvolver a análise apresentada a seguir.

\section{PROCEDIMENTOS METODOLÓGICOS}

Com o objetivo de verificar as diferentes possibilidades de aplicações e uso da tipografia em livros digitais informativos, um exemplar foi selecionado como objeto de estudo. A partir das contribuições dos autores apresentados no referencial teórico foi possível estruturar elementos de análise que serão úteis para a inspeção descritiva e qualitativa sobre o artefato escolhido.

\subsection{Objeto de estudo}

O livro digital informativo escolhido para análise foi o "Incredible Numbers" escrito pelo Professor Ian Stewart e desenvolvido pela Touchpress Limited.

Incredible Numbers foi premiado pela Digital Book Award ${ }^{1}$, como melhor app book de não-ficção para adultos do ano de 2015, e selecionado pela Apple como um dos melhores aplicativos do ano de 2014.

O livro busca explorar, por meio de demonstrações interativas, alguns conceitos da matemática com o intuito de tornar claro os mistérios que compõem as teorias.

A partir da capa, Figura 1., o leitor pode escolher um dos oito capítulos, diferenciados pelas cores, ou ainda visualizar conceitos que estão disponíveis como glossário, ao tocar nos elementos em cor cinza.
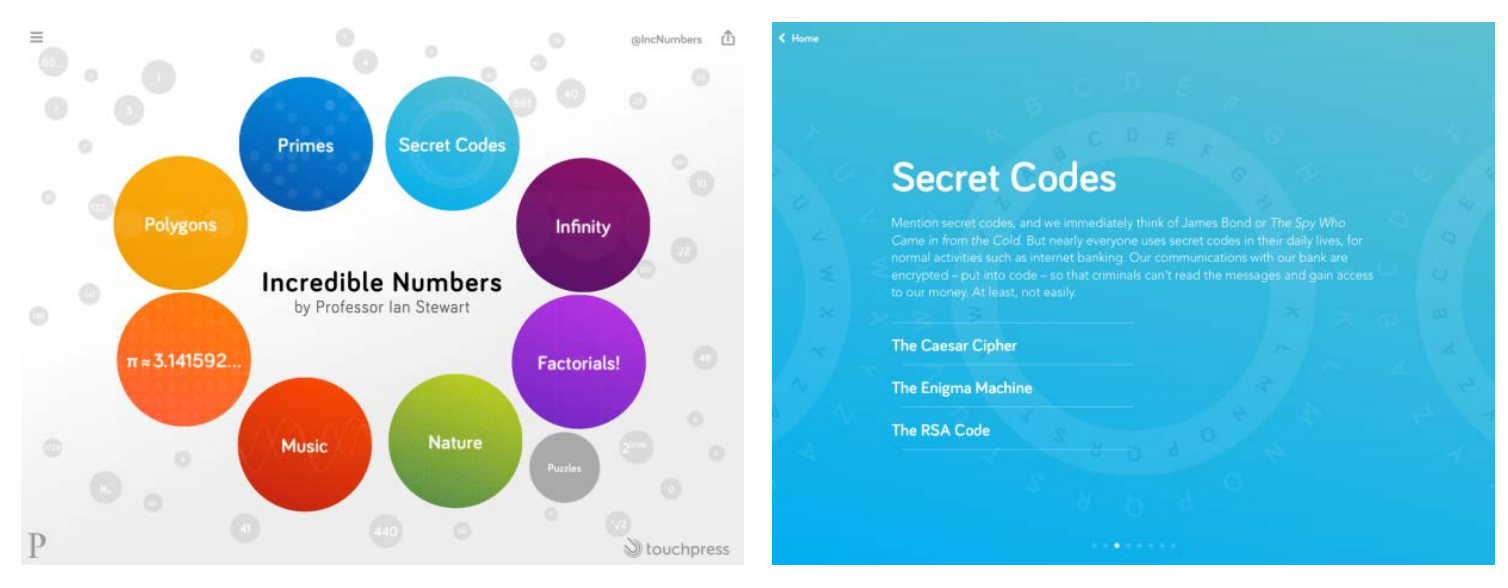

Figura 1. Capa do livro e entrada de capítulo.

Fonte: captura de tela.

Ao abrir uma sessão do capítulo, o conteúdo fica disposto em uma coluna principal com rolagem vertical. Informações complementares são sinalizadas no texto, mudando a cor da tipografia. Assim, ao tocar na expressão, uma página com as

\footnotetext{
${ }^{1}$ Prêmio literário anual que destaca a inovação, a criatividade e a excelência em todos os aspectos do livro digital. Disponível em: < http://www.digitalbookworld.com/2015/winners-of-the-2015-digitalbook-awards-announced-at-gala-hosted-by-ira-wolfman/>. Acesso em mar 2016.
} 
informações é exibida. Quando a cor não é alterada mas a expressão é sublinhada, indica que uma nota complementar pode ser visualizada na mesma página.

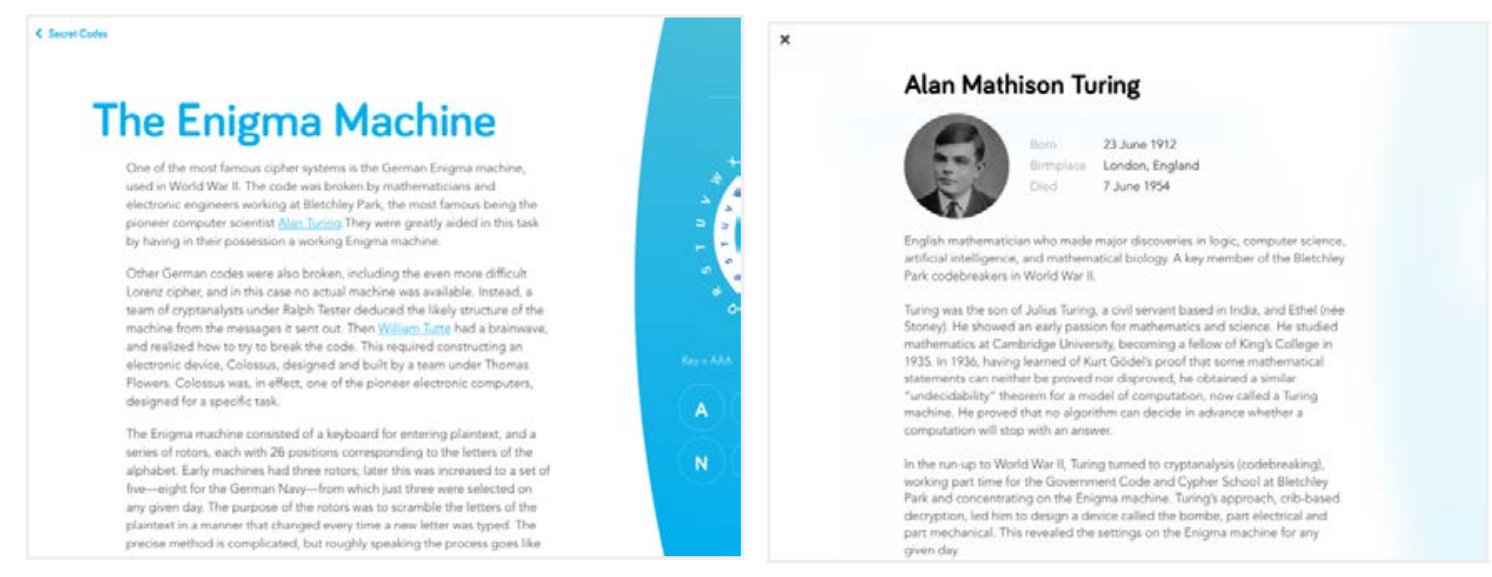

Figura 2. Páginas no capítulo.

Fonte: captura de tela.

O leitor tem acesso a mais conteúdo interativo, que fica disponível na lateral da página. Nessa página, as explicações são apresentadas na barra inferior para apoiar as interações e orientar o leitor sobre o conteúdo.
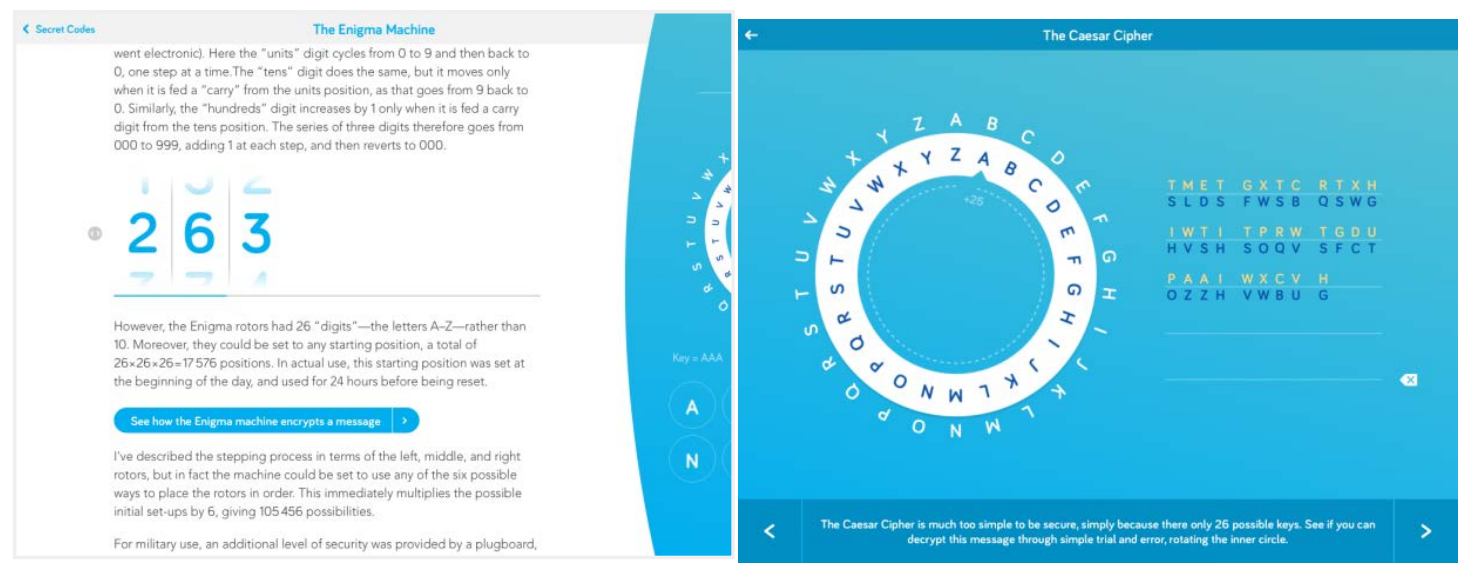

Figura 3. Páginas no capítulo

Fonte: captura de tela.

\subsection{Resultados}

Estruturar a análise permitiu evidenciar aspectos da tipografia em um livro digital informativo observados nesse estudo. O resultado das análises é descritos no quadro abaixo. 


\begin{tabular}{|c|c|c|}
\hline PROPRIEDADES & TIPOGRAFIA ESTÁTICA & TIPOGRAFIA EM MOVIMENTO \\
\hline $\begin{array}{l}\text { Legibilidade e } \\
\text { Leiturabilidade }\end{array}$ & $\begin{array}{l}\text { Nos textos explicativos (Figura 2) o } \\
\text { texto apresenta cor escura sobre o } \\
\text { fundo branco, a fonte escolhida, } \\
\text { juntamente com as cores e } \\
\text { espaçamentos empregados, permitem } \\
\text { a legibilidade dos caracteres e conforto } \\
\text { de leitura. }{ }^{\oplus} \\
\text { Porém, na abertura dos capítulos } \\
\text { (Figura1), onde o texto está } \\
\text { configurado em branco sobre o fundo } \\
\text { colorido, a legibilididade e } \\
\text { leiturabilidade estão comprometidas } \\
\text { pois a fonte escolhida no tamanho } \\
\text { utilizado não tem peso suficiente para } \\
\text { se sobressair na tela, dificultando o } \\
\text { reconhecimento dos caracteres e a } \\
\text { leitura. } \ominus\end{array}$ & $\begin{array}{l}\text { A legibilidade é mantida. } \\
\text { A tipografia em movimento é utilizada } \\
\text { integrada com as interações (Figura 3). } \\
\begin{array}{l}\text { ( } \\
\text { O ritmo e a fluidez são controlados pela } \\
\text { manipulação do leitor durante as } \\
\text { interações. }\end{array}\end{array}$ \\
\hline Espaçamento & $\begin{array}{l}\text { Os espaços empregados (Figura } 2 \text { e } 3 \text { ) } \\
\text { entre letras, linhas e parágrafos nos } \\
\text { textos favorece o fluxo de leitura } \\
\text { contínuo, minimizando as distrações } \\
\text { do leitor. } \oplus\end{array}$ & $\begin{array}{l}\text { O espaçamento utilizado permite o } \\
\text { reconhecimento dos caracteres, mesmo } \\
\text { quando há troca rápida das informações } \\
\text { de números por exemplo (Figura } 3 \text { ). }{ }^{\oplus}\end{array}$ \\
\hline Cor e tamanho & $\begin{array}{l}\text { As cores, assim como a variação dos } \\
\text { pesos e tamanhos da fonte, são } \\
\text { utilizados para diferenciar as funções } \\
\text { da tipografia, como por exemplo } \\
\text { títulos, parágrafos. } \oplus \\
\text { Além disso, pode indicar a presença de } \\
\text { elementos interativos, como botões e } \\
\text { links (Figura } 2 \text { e 3). } \oplus \\
\text { Ainda, as matizes escolhidas } \\
\text { permitem textos e palavras legíveis } \\
\text { junto à luminosidade do dispositivo } \\
\text { quando estão apresentadas em fundo } \\
\text { branco. } \oplus \\
\text { Porém, quando a tipografia em branco } \\
\text { está apresentada em fundo colorido, } \\
\text { estes matizes não proporcionam } \\
\text { grande contraste, também em função } \\
\text { do tamanho e peso da fonte, } \\
\text { dificultando a leitura. } \ominus\end{array}$ & $\begin{array}{l}\text { O contraste é empregado, variando a cor } \\
\text { e o tamanho das letras com matizes que } \\
\text { possibilitam conforto visual ao leitor } \\
\text { (Figura } 3 \text { ). } \oplus\end{array}$ \\
\hline Hierarquia & $\begin{array}{l}\text { A hierarquia tipográfica da página é } \\
\text { consistente mantendo organização e } \\
\text { orientando o leitor na navegação pelo } \\
\text { conteúdo. } \oplus\end{array}$ & $\begin{array}{l}\text { A tipografia em movimento destaca-se } \\
\text { da hierarquia da página como um } \\
\text { elemento especial, principalmente em } \\
\text { páginas que apresentação elementos } \\
\text { interativos compostos a partir da } \\
\text { tipografia. } \oplus\end{array}$ \\
\hline
\end{tabular}

Quadro 1 - Resultado das análises.

Fonte: Elaborado pelas autoras. 


\subsection{Discussão}

A partir do estudo e análise do objeto de estudo, pode-se observar que o livro digital Incredible Numbers valoriza a tipografia em blocos de texto e títulos, como também, utiliza as variações de cor e tamanho para construir a organização da página de modo que o leitor seja orientado pelo conteúdo. É a hierarquia tipográfica que proporciona uma composição organizada da página. Assim, pode-se ressaltar que a interface do livro é clara beneficiando a leitura e as interações.

Nos textos mais longos e explicativos do conteúdo, a tipografia é bem empregada tanto quanto ao tamanho da fonte, quanto ao peso e a escolha das cores que se apresentam em fundo branco. Porém, nas aberturas de capítulo, o texto se apresenta em branco sobre o fundo colorido. Por ser uma fonte com hastes finas, pouco peso, aplicada em um tamanho relativamente pequeno, e também a matiz escolhida não proporcionar muito contraste nestas condições da tipografia, a legibilidade e leiturabilidade do texto é comprometida.

Além disso, a tipografia em movimento possui potencial para favorecer a leitura estética, um vez que tem por objetivo envolver o leitor por meio de aspectos afetivos. As interações que utilizam a tipografia em movimento favorecem a curiosidade e a motivação pelo conteúdo do livro digital informativo, já que o movimento é um apelo à atenção do leitor.

A leitura estética, no livro informativo, pode potencializar a leitura eferente, que, diferente da primeira, tem por objetivo conduzir o leitor pelo conteúdo e ajudá-lo a selecionar as informações que serão úteis posteriormente.

Com referência na análise realizada, observa-se que a tipografia ainda pode absorver melhor as características do meio digital para expandir suas aplicações.

Existe um potencial a ser desenvolvido ao considerar a tipografia no contexto do livro digital informativo, como por exemplo, explorar recursos da tipografia em movimento para integrar a leitura estética e eferente.

\section{CONSIDERAÇÕES FINAIS}

As publicações digitais já são uma realidade no meio informativo. Com isso, muitos recursos vem se reinventando para atender a demanda de leitores que buscam interagir com o conteúdo de forma não linear.

Responsável por compor textos, a tipografia também está se adaptando a este novo meio, e outras formas de uso da tipografia estão surgindo, como a tipografia em movimento que permite mudar a localização dos tipos, piscar, desaparecer, mudar de cor e escala. Neste novo universo da tipografia, retomar alguns conceitos da tipografia tradicional, baseada em publicações impressas, são necessários. Porém, só esta literatura não é suficiente para compreender conceitos e diretrizes principalmente da tipografia em movimento.

Percebeu-se a partir da análise do livro digital Incredible Numbers que a tipografia atende positivamente grande parte das características levantadas, visto que, por ser uma publicação premiada possui qualidades. Entretanto, a tipografia ainda pode ser explorada, nos livros digitais interativos, considerando as possibilidades das mídias digitais. Este recurso gráfico tem potencial para se configurar como um elemento interativo ou como botões que levam o leitor à conteúdos adicionais.

Ainda, é possível dizer que, não são em todos os momentos que a tipografia estática favorece a leitura no livro digital Incredible Numbers. Pode-se perceber a 
pouca legibilidade dos textos em algumas páginas do livro. Isso mostra que, mesmo a tipografia estática, mais próxima da tipografia para publicações impressas, onde encontram-se muitas bibliografias, ainda precisa ser estudada e explorada.

Por fim, cabe ressaltar, que os estudos específicos sobre a tipografia em tela ainda são escasso. Muitos autores ainda tratam a tipografia com referência à sua aplicação impressa, sem expandir para as necessidades da tipografia em ambientes digitais.

\section{REFERÊNCIAS}

BONSIEPE, Gui. Design: do material ao digital. Florianópolis: FIESC/IEL, 1997.

BRANDÃO, João Aranda. Motion Graphics Ergonomics: Animated Semantic System, for Typographical Communication Efficiency. Procedia manufacturing 3, 2015. Disponível em <http://ac.els-cdn.com/S2351978915009658/1-s2.0-

S2351978915009658-main.pdf?_tid=b3bcfdda-149c-11e6-a56000000aacb35e\&acdnat $=1462657574 \_d a 682 f b 8 b 1 c e 5 d 49 b e 082 f d 4 c e 29 c 755>$ Acesso em 04 mai. 2016.

BRINGHURST, Robert. Elementos do estilo tipográfico. Versão 3.0. São Paulo: Cosac Naify, 2005.

BROWNIE, Barbara. Fluid characters in temporal typhography. Fusion issue 1, 2012. Disponível em < http://www.fusion- journal.com/issue/001-fusion/fluid-characters-intemporal-typography/> Acesso em 30 mar. 2016.

CARREAS, C. Libros científicos, atuales y comprensibles. In: Subdirección General de Coordinación Bibliotecaria, 2011. Disponível em: Acesso em: jan 2016.

FARIAS, Priscila. Legibilidade e tipografia. Tupigrafia 3, 2002.

GARRALÓN, Ana. Ler e saber: os livros informativos para crianças. São Paulo: Pulo do gato, 2015.

GARRALÓN, Ana. Ficción e información: tendencias en los livros de conocimentos. In: Subdirección General de Coordinación Bibliotecaria, 2011. Disponível em < http://prensahistorica.mcu.es/es/catalogo_imagenes/grupo.cmd?path=1000127245\& bt=europeanaapi>. Acesso em: jan 2016.

HASLAM, A. O livro e o designer II: como criar e produzir livros. São Paulo: Rosari, 2010.

HOSTETLER, S.C. Integrating typography and motion in visual communication. Cedar Falls, IA, EUA: University of Northern lowa, 2006. Disponível em: <http em: $<$ http://www.units.muohio.edu/codeconference/paprs/papers/soo\%20hostetler20 06\%20idmaa\%20full\%20paper.pdf> Acesso em 30 mar. 2016.

LEEUWEN, Theo van. Towards a semiotics of typography. Information design journal, 2006. Disponível em <http://www.ixdcth.se/courses/2012/tda492/sites/default/files/files/Reading_Toward s_a_Semiotics_of_typography.pdf> Acesso em 04 mai. 2016.

LUPTON, Ellen. Pensar com tipos. São Paulo: Cosac Naify, 2006. 
LUPTON, Ellen. Tipos na tela. São Paulo: Gustavo Gili, 2015.

LUPTON, E.; PHILLIPS, J. C. Novos fundamentos do design. São Paulo: Cosac Naify, 2008.

SAMARA, Timothy. Guia de design editorial. Porto Alegre: Bookman, 2011a.

SAMARA, Timothy. Guia de tipografia. Porto Alegre: Bookman, 2011b.

SANTAELLA, Lucia. Comunicação ubíqua: repercussões na cultura e na educação. São Paulo: Paulus, 2013.

TURGUT, Ozden Pektas. Kinetic typography in movie title sequences. Artsedu, 2012. Disponível em

<http://www.sciencedirect.com/science/article/pii/S1877042812033472> Acesso em 04 mai. 2016. 